Estudios Románicos, Volumen 28, 2019, pp. 331-346

ISSN: 0210-491

eISSN: 1989-614X

DOI: https://doi.org/10.6018/ER/377641

\title{
LA LAISSE CLXXXVII: ESTRUCTURA Y MOTIVOS CÓMICOS EN LA CHANSON DE ROLAND
}

(The laisse CLXXXVII: structure and comical motifs in the Chanson de Roland)

\author{
Roger Navas* \\ Universitat Pompeu Fabra
}

\begin{abstract}
The structure of La Chanson de Roland has been deeply studied by many scholars; the debate surrounding "Baligant" is one of the recurrent topics. In this article, we focus on the laisse cLXXXVII, which is placed at the beginning of the episode, in order to reveal certain structural and semantic parallelisms outside of the framework of the authenticity discussion; we also describe the function of these parallelisms, especially the way in which they help the transition between the two halves of the Chanson; studying the purpose of these symbolic correspondences leads us to look into the existence of comical elements in the text. Accordingly, after a short introduction, the second section is dedicated to a formal analysis of the laisse, the third serves to contextualize it, reconstructing the temporal progression of the story, and, finally, the fourth section studies this comical component and its elaboration on the laisse.
\end{abstract}

Keywords: Epic; Chanson de geste; Humour; Comic; Turoldus.

Resumen: La estructura de la Chanson de Roland ha sido ampliamente analizada, siendo la polémica en torno al episodio de Baligán uno de los temas más frecuentados por la bibliografía crítica. En el presente artículo estudiamos en profundidad la laisse CLXXXVII, una de las primeras del episodio, para, al margen del debate genético, revelar determinados paralelismos de orden estructural y semántico; describimos asimismo la función de estas resonancias dentro de la Chanson, en especial los modos en que ayudan a la transición entre sus dos mitades; y ello nos conduce a investigar un uso puntual de lo cómico en el cantar. Así, tras una breve introducción, en el segundo apartado analizamos formalmente la laisse, en el tercero la inscribimos en el cotexto, reconstruyendo el marco temporal de la historia, y finalmente en el cuarto estudiamos este componente cómico y su plasmación en la laisse.

Palabras clave: Épica; Chanson de geste; Humor; Cómico; Turoldus.

\footnotetext{
*Dirección para correspondencia: Av. Icària 174, 1 2ª , 08005, Barcelona (navas.roger@gmail.com).
} 


\section{Introducción}

Afirma Duggan que el episodio de Baligán transforma la Chanson de Roland, que en principio era un relato de traición y venganza, en "an almost comical struggle of good and evil wherein right triumphs over all that is culturally and religiously strange" (1973: 74). Es éste un argumento utilizado repetidamente por los partidarios de la teoría de la interpolación en la trillada discusión acerca de la autenticidad del episodio, que se inició a finales del XIX y desde entonces ha hecho correr ríos de tinta (De Mandach 1993: 173 y ss.). Martín de Riquer sostenía por su parte que el concepto de autenticidad no era aplicable a cantares de gesta de tradición oral, por lo que la polémica, entendida en estos términos, carecería de sentido, aun cuando desde un punto de vista filológico es posible que "el episodio de Baligant sea uno de los más recientemente incorporados a la Chanson" (nota al v. 2609)1.

En el presente artículo proponemos una lectura original del episodio a partir del estudio en profundidad de la laisse CLXXXVII, que nos revela determinados paralelismos de orden estructural y semántico entre las dos mitades del poema, entre la batalla de Roncesvalles provocada por la traición de Ganelón y la supuesta interpolación de Baligán que retrasa, pero finalmente permite, el juicio de los últimos versos; concluiremos que el maniqueísmo absoluto - cosmológico - que se desprende de esta segunda parte y que Duggan entiende peyorativamente como "almost comical", es efectivamente, en ciertos puntos concretos, intencionalmente cómico. A pesar de que los paralelismos que mostraremos son generadores de coherencia ${ }^{2}$, cabe evidentemente la hipótesis de que sea una coherencia buscada por el autor del episodio de Baligán, genéticamente posterior (Duggan 1973: 77-78): no pretendemos defender una u otra tesis en la controversia académica, sino que creemos, con Jean Maurice, "qu'on a le droit de l'interroger [le texte de la Chanson] au moyen d'une analyse littéraire qui n'en revienne pas toujours à la genèse de l'œuvre" (1992: 52)3.

Reproducimos la laisse en cuestión con el objetivo de facilitar la lectura del análisis que sigue:
2570
Li reis Marsilie s'en fuit en Sarraguze, suz un'olive est descendut en l'umbre.
2572 S'espee rent e sun elme e sa bronie, sur la verte herbe mult laidement se culcet.

\footnotetext{
1 Utilizaremos la edición de la Chanson de Roland de Riquer, referenciada en la bibliografía.

2 Jean Rychner fue el primero en destacar y analizar rigurosamente la «forte cohérence» de la Chanson de Roland (1955: 47). A pesar de que haremos consideraciones en este sentido, nuestro estudio no está centrado - como ya han hecho exhaustivamente gran cantidad de investigaciones desde entonces - en ampliar el trabajo de Rychner discutiendo la configuración estrófica del poema y si es mejor dividirlo en tres, cuatro o cinco partes, sino que dedicaremos nuestra atención a distintas elaboraciones simbólicas concretas. Por lo demás, y como justifica Vallcorba al estudiar el tema de la pasión (2010: 107-133), estamos de acuerdo con Rychner en que la muerte de Roldán es el punto culminante del poema (1955: 39), y hemos de señalar que sólo tras este clímax pueden aparecer los motivos cómicos que analizaremos.

3 Las cursivas de la bibliografía crítica, si no se especifica lo contrario, son del original; las cursivas del texto de la Chanson son evidentemente nuestras.
} 
2574 La destre main ad perdue trestute, del sanc qu'en ist se pasmet e angoiset.

2576 Dedevant lui sa muiller Bramimunde pluret e crient, mult forment se dolusent;

2578 ensembl'od li plus de $\cdot \mathrm{XX} \cdot$ mil humes, si maldient Carlun e France dulce.

2580 Ad Apolin en curent en une crute, tencent a lui, laidement le despersunent:

2582 «E, malvais deus! por quei nus fais tel hunte?

Cest nostre rei por quei lessas cunfundre?

2584 Ki mult te sert, malvais lüer l'en dunes.»

Puis si li tolent ses ceptre e sa curune,

2586 par mains le prendent sur une culumbe, entre lur piez a tere le tresturnent,

2588 a granz bastuns le batent e defruisent.

E Tervagan tolent sun escarbuncle,

2590 e Mahumet enz en un fosset butent e porc e chen le mordent e defulent.

\section{Funcionamiento narrativo de la laisse}

La laisse relata la llegada a Zaragoza de Marsil derrotado y la consiguiente revuelta, que conduce a la destrucción de ídolos religiosos. Se desarrolla, pues, en dos escenarios: Marsil, gravemente herido, está con Bramimonda a la sombra de un olivo, pervirtiendo así el tópico del locus amoenus, puesto que con ella están veinte mil hombres furiosos que desplazan el lugar de la acción dirigiéndose hacia la gruta donde están los ídolos 4 . No obstante, el análisis formal nos mostrará que debemos evitar separar esquemáticamente estos dos espacios.

No es habitual en el francés antiguo la construcción sintáctica con la que arranca la laisse: sólo en un 17\% de los enunciados de la Chanson se encuentra el sujeto antes que el verbo (Marchello-Nizia 1995: 73). Aunque conviene proceder con cautela al señalar una formulación como estilísticamente relevante en base a este tipo de consideraciones, sí parece evidente que la ordenación es significativa, que existe "un principe d'organisation informationnelle" (Bacha 2004: 23) según el cual el elemento tematizado ("Li reis Marsilie") encabeza el enunciado. No en vano, las dos oraciones que siguen tienen a Marsil como sujeto omitido, empezando con objetos nominales referidos a él ("s'espee", "la destree main"); y a continuación se lo toma como punto de referencia espacial ("dedevant lui"). La sintaxis nos revela la estructura bipartita de la laisse; Bramimonda desplaza a Marsil como sujeto e introduce así el segundo núcleo informativo: la destrucción de los ídolos que tiene lugar "en une crute", cláusula que, al igual que "en Sarraguze", se halla precedida por un verbo que describe un movimiento rápido,

$4 \quad$ Hay quien ha interpretado este pasaje en clave feminista (Kinoshita 2006: 36 y ss.). 
configurando así una isotopía de caos y agitación —atmósfera que domina gran parte de las descripciones de los paganos (Vander 2017: 22).

Diferenciamos pues dos partes, pero es sabido que estos dardos de sentido que son las laisses presentan una fuerte coherencia interna. Encierran, como las distintas celdas de un vitral, una única idea, por mucho que esa idea pueda tener varias caras. Marsil se desmaya al llegar a Zaragoza y, entonces, su mujer, en frente suyo, lidera una revuelta que destroza los ídolos de la ciudad. Lo que a un lector moderno le podrían parecer simplemente dos acontecimientos concatenados son en realidad dos matices, dos aspectos de un mismo bloque de sentido: el final de la huida de los sarracenos, perseguidos bajo el sol inmóvil por Carlos. Evidentemente, siguen siendo dos sucesos narrativos, y el lector que los entienda sin tener en cuenta el monolitismo de la laisse comprenderá perfectamente que ambos derivan de la retirada de Marsil, pero lo que queremos subrayar es que la relación entre ambos sucesos la hemos añadido nosotros. Apuntábamos que el verso 2576 prepara la transición a la segunda parte de la laisse, que comprende los versos 2580-2591: la atención pasa de Marsil a Bramimonda y de esta a los hombres que se rebelan contra sus dioses. Aunque esta secuencia exista, la conforman fogonazos aislados, y no hay elementos textuales que faciliten el paso fluido de un momento a otro. Sólo el "puis" que precipita la violenta conclusión de la laisse introduce cierta relación temporal entre los hechos, aun cuando esa relación es la de un salto abrupto, como la que se establecía en el plano espacial con el "dedevant"; en todo caso, es manifiesta la despreocupación por explicitar los nexos espaciotemporales y causales. La parataxis es la forma de articulación imperante (Auerbach 1988: 108 y ss.): las acciones se colocan una al lado de otra generando un paradójico - pues se trata de acciones intrínsecamente dinámicas - clima de estatismo, una "sensación de atemporalidad o congelación del tiempo" (Vallcorba 2010: 65). Una coordinación por medio de la conjunción " $\mathrm{y}$ " no alteraría en nada el carácter esencialmente paratáctico del texto; al destacar su ausencia lo que queremos señalar es precisamente la identidad que debemos establecer entre la llegada de Marsil derrotado y la revuelta: son uno y lo mismo.

Esta comprensión formal de la laisse se confirma si tomamos en consideración el modo en que son tratados los sarracenos a lo largo del poema: se presentan como un "ensemble homogène, trop sommairement appréhendé pour qu'en ressortent des individus problématiques", como un grupo extraño definido únicamente por su otredad y que, por tanto, "mobilise dans le texte la categorie à multiples facettes du merveilleux" (Maurice 1992: 94). Se afirma repetidamente su relación con lo diabólico y, puesto que Marsil y Baligán no dejan de ser personajes que cabe interpretar por simetría con respecto al pueblo franco - del mismo modo en que Roldán y Carlos se encuentran en continuidad con la esfera de lo sagrado-, están especialmente cerca de estas oscuras potencias sobrenaturales y de los (inexistentes) dioses paganos; en el caso que nos ocupa, es evidente que las estatuas de la segunda parte son un desdoblamiento del rey sarraceno.

Ya hemos mencionado cómo el "en curent" era un eco del "s'en fuit". Esta resonancia se ve reforzada topológica y quizás incluso lumínicamente: Marsil baja del caballo a la sombra de un olivo y su pueblo baja a una gruta (que cabe suponer oscura). El 
vínculo de equivalencia entre los inicios de ambas partes se termina de sellar mediante la reaparición del adverbio "laidement" (vv. 2573 y 2581); aunque pueda parecer que la repetición apuntala el paralelismo tan solo en el plano de la expresión (pues "laidement" se refiere en primer lugar a la forma en que se estira Marsil y en segundo lugar a cómo el pueblo insulta a los ídolos, acciones en principio inconexas), también lo desarrolla en el plano del contenido, puesto que si se inscribe la laisse en el cotexto - como haremos en el próximo apartado - tales acciones sí activan sentidos concomitantes. Cabe matizar que el léxico del francés antiguo es limitado y que la repetición es inherente a la escritura formular; sin embargo, suscribimos la tesis de Heinemann según la cual en ciertos versos "[el escritor] se sert de la répétition des mêmes mots pour évoquer dans l'un des deux passages le souvenir du même messème dans l'autre" (1973: 19)5.

Antes de ubicar la laisse en el conjunto de la Chanson, debemos dejar constancia de otra repetición prácticamente literal que prolonga el efecto especular: "main"-"mains" (vv. 2574 y 2586). En este caso, no existen sentidos implícitos - a los cuales se acceda a través del cotexto - en consonancia, sino que nos encontramos con una relación de marcada oposición: Marsil pierde su mano, mientras que sus vasallos usan las suyas para derribar estatuas ${ }^{6}$. Dicho contraste, puesto en relieve por la literalidad de la repetición, llama la atención sobre una triple inversión que, a pesar de ser más sutil, es total: todos los objetos de los que se desprende Marsil ("espee", "elme", "bronie", v. 2572) hallan una correspondencia, en el mismo orden de aparición, con los que roban o destrozan los insurrectos ("ceptre", "curune", "culumbe", vv. 2585-2586). Si bien la tercera asociación no es tan manifiesta como las dos primeras, por estar "culumbe" dislocado textualmente y por ser un elemento arquitectónico y no una pieza con la que el Rey pudiera equiparse, el hecho de que "ceptre", "curune" y "culumbe" sean símbolos por antonomasia del poder nos lleva a entenderlos conjuntamente; así, la evidente cercanía formal entre la espada y el bastón y entre el yelmo y la corona nos impone un paralelismo no tan inmediato entre la cota y la columna. Aunque difícilmente trazaríamos esta última simetría sin la presencia de la serie, no resulta descabellada en sí misma: es plausible una semejanza visual entre la columna sobre la que descansaría el ídolo - quizás sin piernas - y el torso de Marsil. Recordemos finalmente, sin ánimo de entrar en lecturas de corte numerológico, la importancia de los grupos de tres - en la misma laisse tenemos la trinidad sarracena: Apolín, Tervagán y Mahoma.

Por otro lado, puede argumentarse - y no es una resonancia excluyente con respecto a la que acabamos de comentar - que "le prendent sur une culumbe" constituye una referencia espacial que entronca con "suz un'olive est descendut". Aunque se produce una inversión en quien ejecuta el acto de bajar (los ídolos son pasivos y el rey es activo), estaríamos ante otra relación que funciona por paralelismo (rey e ídolos descienden de

$5 \quad$ El «messème» sería el sema invariable detrás de todas las fórmulas potenciales para una misma situación. Heinemann destaca las fórmulas de complementos circunstanciales de modo (es el caso) como aquellas en las que es más fácil identificar el «messème» (1973: 13). El «messème» aquí presente corresponde al significado de "paganamente". De este modo, aunque el pueblo se oponga al rey, uno y otro quedan homogeneizados mediante esta recurrencia.

6 Cabe recordar las connotaciones que tiene en el mundo árabe el hecho de perder la mano: era el castigo aplicado a los ladrones, que podían ser así identificados socialmente, convirtiéndose en parias. 
todos modos) y no por oposición (como la que mencionábamos entre perder la mano y usar las manos para destrozar los ídolos). Tal relación implicaría una visión de la columna como árbol que es, de nuevo, plausible tanto a un nivel puramente plástico como simbólico. La polivalencia asociativa de la columna del texto — que remitiría tanto al árbol como al torso de Marsil- es la misma que está atestiguada en el imaginario del siglo XII, cuando a la comprensión forjada durante el arte paleocristiano de la columna como árbol se añade el significado de la columna como hombre, significado que ya existía con anterioridad, pues "[it] goes back to the idol" (Bandmann 2005: 75).

\section{Cotexto y temporalidad}

A pesar de la fuerte autonomía formal y semántica de cada laisse, existe un engarzamiento entre ellas; de lo contrario, no habría historia. Las celdas del vitral, aunque separadas, forman un conjunto. ¿Cómo se construye esta narración forzosamente sincopada? A través de lo que Ray denomina el "paradigm of pairing" (1976: 245), de la constante recapitulación, como si el relato, para avanzar, necesitara resituar a todos los actores implicados. No obstante, lo que denota esta manía reiterativa, este continuo volver a empezar que deriva directamente de la unidad de la laisse, es justamente la "lack of awareness of the past as informant of the future" (Ray 1976: 248): precisamente porque el texto no se rige por una lógica causal en la que el presente se desprenda del pasado, aparece el imperativo de recordar el pasado, de repetir una información que no se considera implícita en la situación presente.

No obstante, el "pairing", el retomar la narración con información redundante, no debe entenderse de un modo literal, ya que la dimensión vertical, trascendente, tipológica predomina sobre la horizontal, histórica - aunque cabe recordar que la concepción figural se caracteriza por mantener siempre "la historicidad real" de lo que es, además, interpretado en clave simbólica (Auerbach 1998: 100). Así, nuestra laisse enlaza con la anterior mediante "negative equivalency" (Ray 1976: 246): el primer verso retoma el último de la laisse previa mediante la relación entre "Carles" y "li reis Marsilie" (vv. 2569-2570); este tipo de ilación es uno de los más habituales: el contraste entre francos y paganos se traslada a la construcción textual de modo que "la catégorie de l'opposition acquiert une portée structurelle" (Maurice 1992: 59). El encadenamiento refuerza colateralmente la estructura interna a la que nos hemos referido: el último verso de la primera parte - completamente prescindible tanto sintáctica como semánticamentevuelve a mencionar a "Carlun" (v. 2579), generando un efecto de circularidad.

El texto atribuye, mediante la técnica de la recapitulación, gran importancia al pasado inmediato al momento que está narrando; sin embargo, esta gravedad temporal en torno al presente - hay también, en la otra dirección, hacia el futuro, "a total preoccupation with the imminent" (Ray 1976: 248) - convive con una cuidada estructura global que "témoigne chez le poète d'un certain goût pour l'ironie et surtout d'une tendance marquée pour des modalités d'expression doubles" (Brault 1971: 5).

El trabajo de organización del texto en su conjunto se hace evidente en los sueños premonitorios de Carlos: en el hecho de que en las laisses LVI y LVII se anticipe así ale- 
góricamente el desarrollo narrativo del cantar y, además, en la reaparición del motivo en las laisses CXCV y CXCVI. En este segundo bloque de sueños opera el principio de "l'encastrement en tête", que es específico del episodio de Baligán — se trata por lo demás del único mecanismo que se opone a una disposición de los materiales más lineal que en la primera mitad del cantar (De Mandach 1993: 178-181). Por otro lado, cabe destacar que estos dos sueños están encapsulados, a diferencia, significativamente, de los primeros, por la aparición del ángel Gabriel (vv. 2526 y 2568); el componente religioso es ahora más acusado. El paralelismo en el contenido de ambos grupos de visiones es manifiesto; incluso, como señala Riquer en la nota al verso 735 , se puede interpretar que la segunda visión del primer bloque anuncia exactamente lo mismo que la segunda del segundo. Pero, además, estas segundas revelaciones se insertan en un complejo juego temporal en el que participan múltiples desarrollos narrativos y que es clave para estudiar adecuadamente nuestro texto ${ }^{7}$.

Nos encontramos al final del quinto día de la Chanson, "el día más problemático en lo que se refiere a su delimitación" (Vallcorba 2010: 26), y hemos dejado a Carlos dormido "tresqu'al demain, al cler jur" (v. 2569); el "en l'umbre" nos pone en alerta sobre una posible anacronía: ¿llega Marsil a Zaragoza el día siguiente a su derrota o hemos retrocedido a un momento anterior en la historia? El "oi matin" posterior (v. 2601) obliga a descartar la primera opción y confirma que efectivamente estamos ante una analepsis. Por lo que se produce un contraste irónico: mientras los francos acampan agotados, plácidamente y sin centinelas - el texto recalca que los soldados se duermen "cuntre tere" (v. 2494) y que hasta los caballos se estiran (v. 2523) - , los sarracenos se rebelan dirigiéndose a la gruta (bajo tierra) y atacando los ídolos. La acción se presenta pues bajo la forma de lo que en la poética medieval se denominaba ordo artificialis, del que - conviene recordar - se valoraba la capacidad para "convey meaning by abandoning strict chronology" (Green 2002: 98).

Pero no es este el único contraste al que da pie la ordenación de los hechos. El quinto día es un día increíblemente largo, tanto en lo que respecta al récit como, situándonos dentro de la histoire, desde un punto de vista estrictamente empírico: el milagro del sol solicitado por Carlos lo prolonga. E incluso podría extenderse más: cuando finalmente cae la noche y el rey franco recibe las visiones de Gabriel, el que será su antagonista en la segunda mitad del cantar, Baligán, está remontando el Ebro, iluminando el mar con tal intensidad que "tut li païs en reluist e esclairet" (v. 2637). Sin embargo, no deja de ser de noche. Tras la detención lírica de la imagen (se nos dice que a causa del resplandor "par la noit la mer en est plus bele", v. 2635), se esconde un nuevo contraste irónico que se hace evidente al reconstruir el orden temporal: en la llegada de Baligán a España reencontramos el mismo paradigma semántico (luz sobrenatural) que en la

$7 \quad$ La consideración de la temporalidad de la historia —en la que se basa el análisis que sigue — no es en modo alguno evidente. Nos atenemos en ello a la tesis de Walter: «la temporalité narrative apparaît comme un effet de langage, un jeu intra-discursif réglé par des procédures spécifiques» (1989: 60-61), es decir, como una dimensión de la obra que es legítimo abordar desde el propio texto; y ello, incluso si la cultura en la que esa obra se inscribe no le concede una importancia expresa e incluso si, por razones que atañen las peculiaridades propias de cada género literario, en los cantares de gesta no se la tematiza mediante dispositivos narrativos que la representen explícitamente, como sí sucede en cambio en el roman (Walter 1989: 63). 
entrada en escena de Carlos en Roncesvalles — quien, recordemos, se estaba retirando a Aix - , pero reaparece truncado, a menor escala. Así, con este paralelismo se hace participar también la segunda batalla del cantar de la esfera de lo religioso. Menéndez Pidal echaba en falta este componente sacro en el enfrentamiento de Baligán y Carlos (1959: 117-118); si bien es cierto que de una forma más sutil que en el caso de Roldán, sí existe este componente, prolongando precisamente su presencia en la primera batalla.

A pesar de que la distancia entre los dos polos de este contraste que opone la llegada de Baligán al milagro del sol podría restarle, además de claridad, fuerza, lo que se halla entremedio - es decir: nuestra laisse - amplía el sentido de esta simetría deformada añadiéndole matices; la nave de Baligán recupera la imagen de la luz extraordinaria, pero supone también una continuación, una reelaboración, de los planteamientos simbólicos del episodio de los ídolos. Así, el foco que provoca la claridad durante la noche son unas linternas en lo alto de los mástiles, que podemos poner en relación con la columna sobre la cual se encuentra Apolín"; máxime, teniendo en cuenta que las "lanternes" constituyen un sintagma nominal en coordinación con "carbuncles", los cuales remiten al "escarbuncle" de Tervagán. El texto insiste en estos dos objetos coordinados mencionándolos de nuevo, aunque en orden inverso, en la laisse subsiguiente; son el único elemento que se retoma literalmente en estas dos laisses similaires: "carbuncles e lanternes" (v. 2633) y "lanternes e carbuncles" (v. 2643). La inversión de los términos, aparte de ser hasta cierto punto una muestra de virtuosismo poético, tiene ciertas connotaciones negativas: por un lado, la mera operación lingüística puede ser un síntoma de indiferencia o falta de consideración por parte de la voz narrativa, y potencia la misma sensación de multiplicidad que impregna todo el episodio de los ídolos; por otro lado, tampoco es positivo el trasvase de significado entre los términos cuyo orden se está invirtiendo, pues subraya la idolatría de los sarracenos al poner en un mismo nivel la luz (inmaterial) y los rubíes (materiales), aunque es innegable cierta ambivalencia, tratándose de "luxes condamnables et condamnés [...], mais tellement enviables..." (Maurice 1992: 100). En conjunto, la relación entre los tres acontecimientos (milagro de Carlos, ídolos destruidos, barco de Baligán) no resulta muy favorable para los sarracenos; cabe argumentar incluso que prefigura su derrota en el segundo enfrentamiento militar, puesto que en vez de la ayuda divina que reciben los francos, reciben la ayuda de Baligán, que el texto presenta a priori como insuficiente, como simétrica a la carolingia pero no equiparable, a través de las resonancias simbólicas que acabamos de comentar y sirviéndose de cierto componente cómico que expondremos con más detalle a propósito de nuestra laisse.

Pero, terminando de situar la laisse, es necesario exponer un último paralelismo suscitado por la condensación de múltiples desarrollos narrativos en la noche del quinto al sexto día. Hemos contrapuesto el reposo de los francos con la agitación de los sarracenos; podemos preguntarnos ahora si tal relación de oposición se extiende a los respectivos reyes. Carlos no se desarma y "sun grant espiet met a sun chef" (v. 2497);

8 Es oportuno recordar que en la mitología grecorromana Apolo era el dios de la luz y del sol. Es arriesgado, no obstante, hacer hipótesis alguna acerca del conocimiento que de ello podía/n tener el/los escritor/es de la Chanson. 
Gabriel estará "tute noit a sun chef" (v. 2528) induciéndole visiones. Marsil sí se desarma al llegar a Zaragoza y "mult laidement se culcet". El contraste parece, por tanto, mantenerse. Además, es posible confrontar también los contenidos de los sueños premonitorios con la revuelta que se produce durante el desmayo de Marsil, revuelta que, aun si se da realmente, tiene un componente onírico. Así, observamos un rasgo común a ambas escenas: del mismo modo que Carlos recibe las quejas de los treinta osos (los familiares de Ganelón), reproducidas en discurso directo, las divinidades paganas contiguas conceptualmente a Marsil— son objeto de las acusaciones de los sarracenos, que también se nos trasladan en discurso directo. Nos podemos apoyar en la repetición en la laisse del adverbio "laidement" para argumentar que efectivamente las increpaciones a los ídolos se encuentran en relación con la pérdida de conciencia de Marsil; la reaparición del término en apenas siete versos nos retrotrae intuitivamente a su desmayo, que remite a su vez a los sueños de Carlos, en los cuales hallamos un elemento parecido a las protestas de los sarracenos (las de los treinta osos) que cierra o certifica la relación; de este modo, como afirmábamos al examinar la laisse autónomamente, el cotexto tiende un puente entre los dos hechos.

En las increpaciones de los sarracenos a sus ídolos, además - y en relación con la ambivalencia que comentábamos a propósito del lujo del barco de Baligán—, hallamos el mismo campo semántico (el relativo a las posesiones materiales) que se aplica a lo largo de todo el cantar a la traición de Ganelón: "malvais lüer l'en dunes" (v. 2584); específicamente, durante la primera batalla los francos insisten constantemente en que no se dejarán vender por poco. La laisse siguiente ahonda en esta relación entre los dioses paganos y las acciones de Ganelón al hablar directamente de traición: "li nostre deu i unt fait felonie" (v. 2600). Observamos que este paralelismo, aunque sea entre una cuestión terrenal y otra espiritual, pone en funcionamiento esquemas análogos del lado franco y del sarraceno, difuminando así por momentos la sólida frontera entre identidad y alteridad - si bien, como analizaremos a continuación, existe un marcado tono despectivo y cómico en el tratamiento de esta otredad.

Así pues, nuestro pasaje actúa a modo de bisagra, articulando el episodio de Baligán y la segunda batalla de la Chanson. Lo hemos ubicado señalando algunos de sus ecos simbólicos con las laisses circundantes; no obstante, quizás por el funcionamiento del propio texto, no lo hemos contextualizado narrativamente, "horizontalmente", explicando las causas de lo que en él sucede. La ira de los sarracenos contra sus dioses se debe a la ausencia de milagro en la huida: las aguas del Ebro no se abren y los paganos se ahogan. Siguiendo ese "certain goût pour l'ironie" del que hablaba Brault, la falta de intervención divina se halla anticipada en la laisse LIV (los mensajeros paganos le dicen a Carlos que aquellos que no se han convertido al cristianismo han muerto ahogados) ${ }^{9}$

9 Comenta Maurice a propósito de este suceso que los paganos reniegan de sus símbolos involuntariamente, «à leurs corps défendant, puisque ceux qui refusent l'immersion au baptême se condamnent à la noyade» (1992: 65). Es evidente que en esta imagen se plasma la reticencia de los paganos a abandonar el islam; y nos parece también claro que el relato de la retirada fallida en el Ebro recoge los significados de este episodio para mostrar cómo, a pesar de esta resistencia, los francos los obligan a dejar su religión; por ello, es perfectamente coherente que los paganos restantes, en Zaragoza, destrocen los ídolos, y lo es no sólo desde un punto de vista narrativo, como consecuencia de la falta de intervención divina, sino también simbólico, en relación al conjunto del texto. 
y quizás también en la CLXv: Roldán no llega a beber del agua de Roncesvalles, pero sus enemigos, como si fuera él quien los matara, mueren en ella (aunque se trata de otro curso de agua). Y Baligán entrará en escena remontando el Ebro; como decíamos, aunque no se llega a prefigurar claramente su derrota - que, no obstante, es evidente, pues no hay intriga en el cantar (Duggan 1973: 78) - , se puede intuir en algunas resonancias como ésta ${ }^{10}$.

Nuestra laisse da paso a la segunda mitad de la obra; y en este espacio de transición se filtra cierta distensión cómica en la que nos queremos ahora concentrar. Podemos empezar a tratar esta cuestión confrontando la laisse que estudiamos en mayor profundidad, la clXXXVII, con la cCLXVI, que, además de volver sobre el motivo del bautismo forzado, vuelve también sobre el de la destrucción de ídolos.

\section{Aspectos cómicos}

En efecto, en la laisse cClXvi se relata la entrada definitiva de los francos en Zaragoza y son ahora ellos quienes, "a mailz de fer e a cuignees" (v. 3663) y no con "granz bastuns" (v. 2588), destrozan los ídolos restantes; no obstante, en esta segunda variación del motivo, "the action is described with a minimum of detail and is quite devoid of comical quality" (Herman 1971: 19, nota 18). Así, comparativamente, se ilumina la desproporción de nuestra laisse. La simple extensión que se le otorga a un tema anecdótico, sobre todo considerando el hieratismo del conjunto, puede tener intenciones cómicas. Sin embargo, si sólo hubiera esta falta de adecuación entre récit e histoire, sería difícil hablar de comicidad. Además, conviene remarcar que esta desproporción nos resulta particularmente llamativa porque en nuestro horizonte de expectativas moderno la vinculamos a la ironía (Ballart 1994: 329-337): el texto se alarga sobre algo aparentemente insignificante para volverlo significativo mediante segundos sentidos; no es el caso, pues aquí no se nos está queriendo decir nada más allá de lo aparente, aunque lo aparente era probablemente más cómico en el horizonte de expectativas de la época.

Podemos ilustrar este procedimiento consistente en generar un tono jocoso deteniendo el ritmo de la acción dramática del cantar y multiplicando las descripciones sobre una cuestión menor con otro ejemplo que debemos comentar de todos modos, pues prolonga y aumenta el efecto cómico de nuestra laisse. Baligán, antes de llegar, envía unos emisarios a Marsil; estos dos mensajeros atraviesan diez puertas y cruzan cuatro puentes (vv. 2686-2704). Como comenta Vallcorba, los números pares, connotados negativamente, se asocian a los sarracenos (2010: 55); pero, además, lo hacen aquí de un modo insistente. El texto se extiende de nuevo sobre un asunto trivial, sin por ello cargarlo con un sentido oculto como haría un texto moderno: las puertas y los puentes no encierran ningún significado doble que los haga cómicos, y si lo son es por el simple efecto de repetición y por su pura denotación con números pares; el hecho de que sean pares multiplica su presencia pero no da pie propiamente a connotación alguna, sino

10 Por lo demás, la estrategia de entrar en la península por el Ebro es históricamente plausible (De Mandach 1993: 184). 
que es algo negativo de por sí, sin que el público tenga que descifrar un contenido implícito. Por otro lado, se nos está relatando otra llegada a Zaragoza, la de los mensajeros, que puede evocar la de Marsil, quizás risible por la cobardía que implica.

Y, además, en este episodio de los mensajeros se hace referencia explícitamente a nuestra laisse: la ciudad está conmocionada, el pueblo "pleignent lur deus, Tervagan e Mahum / e Apollin, dunt il mie n'en unt" (vv. 2696-97). No tienen dioses porque ellos mismos han destrozado los ídolos: el bardo ironiza —en estos versos sí- sobre la idolatría de los paganos de una forma cómica ${ }^{11}$. Los mensajeros dejan sus caballos "dedesuz un'olive" (v. 2705), lo que refuerza el mencionado paralelismo con la llegada de Marsil a Zaragoza; en ambos casos el olivo remite, siguiendo la tradición cristiana, a "la falsedad e hipocresía del infiel" (Vallcorba 2010: 113) ${ }^{12}$. Bramimonda les informa entonces de que el rey ha perdido la mano derecha, por lo que - la deducción lógica la hacemos nosotros - no podrán cumplir su cometido, que consistía en enfundarle un guante de oro. Se redobla aquí el efecto que acabamos de comentar: los sarracenos echan en falta ahora, además de los ídolos, la mano de su rey - rey e ídolos que nuestra laisse, como hemos visto, asimilaba formalmente. Subyace en este episodio, acrecentando su ironía, el guante que Carlos da a Ganelón y que "quant li dut prendre, si li caït a tere" (v. 333); el hecho de que este otro guante sea de oro incide en la peripateia, en la inversión (recordemos la idea de la primera mitad del cantar de que los francos no se venderán por poco), y recalca por otro lado el materialismo, la idolatría, de la religión pagana, como también lo hará la promesa de Baligán a sus dioses: "tutes tes ymagenes ferai d'or fin" (v. 3493).

Volviendo propiamente a nuestra laisse, el efecto burlesco del episodio se detecta no solo en el hecho de que, en el marco solemne de la gesta, se le dedique un espacio textual improcedente a un asunto menor, sino también en el tono de irrisión palpable en algunos de los procedimientos retóricos. La anáfora en "e" de los tres últimos versos, si bien es habitual en el cantar, contribuye al clima de desorden y crea cierto desenfreno en la cadencia del poeta, que acumula de este modo elementos para exacerbar la bajeza de los sarracenos. Asimismo, las aliteraciones, que no dejan de ser un tropiezo del lenguaje en su progresión horizontal, denotan una despreocupación por el tema a través de la que se infiltran ridiculez y comicidad: ¿dónde "en curent" los paganos? "En une crute" "3; ¿qué hacen con los "bastuns"? "Le batent”; esta última políptoton duplica la presencia del arma, destacable por otras razones que comentaremos en breve.

Reencontramos esta figura retórica usada con los mismos fines en la primera intervención de Baligán en el cantar: "Oiez ore, franc chevaler vaillant: / Carles li reis, l'emperere des Francs, / ne deit manger se jo ne li cumant" (vv. 2657-2659). Aquí, a la

11 Hablar de ironía es, sin embargo, incurrir en un anacronismo: la ironía situacional de este tipo no se calificó como "ironía” hasta la época moderna (Schoentjes 2001: 48-74).

12 Se trata del mismo simbolismo que se activaba en los primeros versos del cantar, en los que Marsil ordenaba a sus mensajeros: «Branches d'olives en voz mains porterez» (v. 72); observamos pues una búsqueda de coherencia en la construcción del cantar, que por lo demás aumenta el efecto irónico de nuestra laisse.

13 En otras ediciones de la Chanson se desestima en este verso el manuscrito de Oxford y se opta por otras variantes, con lo cual se pierde la aliteración. Sin embargo, aparte de Riquer, la edición crítica de Segre (2003) también se mantiene fiel al texto de Oxford, como ya lo hiciera Bédier. 
repetición de la "o" se le suma el estancamiento en "chevaler", abultado por dos adjetivos. Además, se da la ironía de que no son "franc" (del reino de los francos), y por tanto las palabras del emir se desmienten a sí mismas: tampoco serán "franc" (nobles). La curiosa referencia de Baligán a la comida nos lleva a un último campo que podría justificar la lectura cómica de algunos pasajes de la Chanson; lo cómico se asocia a lo bajo, y convive de un modo particular con lo grotesco.

Herman señala la laisse que hemos estudiado y el episodio en que los cocineros apresan a Ganelón como dos de los pocos momentos deliberadamente cómicos en el cantar (1971: 17-20). Sin embargo, los trata separadamente. Nuestra hipótesis es que, conscientemente o no, el poeta remite a unas mismas imágenes al introducir puntualmente el humor, y que, además, estas dos escenas están también en contacto gracias a una tercera que nada tiene de cómico: la muerte de Roldán. Al oír el tañido del olifante, Carlos ordena que Ganelón sea custodiado por cien pinches de cocina; el texto nos detalla entonces sus padecimientos, entre los cuales están los golpes que recibe: "ben le batirent a fuz e a bastuns" (v. 1825). Creemos que el paralelismo con la destrucción de los ídolos es manifiesto; son estas, además, las dos únicas ocasiones en toda la obra en que aparecen "bastuns", que remiten a lo popular y jocoso ${ }^{14}$.

Por otro lado, como decíamos, las dos escenas también se entrelazan a través de la muerte de Roldán. La tortura de los cocineros, como sí menciona Herman, "serves as a prelude to the more terrible scene of Ganelon's punishment (vv. 3694-3673)" (1971: 18), en la que - como analizó Foucault en referencia a la época clásica (1978: 1137) - el suplicio sirve como una mostración del poder del rey, que realiza la justicia vengándose públicamente. La muerte del traidor contrasta axiológicamente con la de Roldán, el guerrero que muere de forma cristiana y batallando ("devers Espaigne est en un pui agut", v. 2367). Es esta cuestión, el modo de morir y la necesaria protección del cadáver, lo que zanja la segunda disputa entre Roldán y Oliveros: el arzobispo — "qui fut sages e proz" (v. 3691) — le hace ver que tañendo el olifante mantendrá a salvo sus cuerpos: "n'en mangerunt ne lu ne porc ne chen" (v. 1751); y es en este verso en concreto, dentro del contexto que acabamos de exponer, donde a nuestro entender se vinculan el episodio de los ídolos y el del apresamiento de Ganelón. Recordemos: los ídolos - en particular el de Mahoma - identificados formalmente con la persona de Marsil, terminan "en un fosset" donde "porc e chen le mordent e defulent" 15 ; Ganelón, maltratado por unos cocineros, termina con su cuerpo diseminado por un campo francés por el juicio de Carlos; Roldán, por el contrario, explicita que, aun

14 Herman menciona por otras razones el motivo cómico de las armas rudimentarias (1971: 15). Es difícil determinar con precisión histórica cómo eran y qué importancia tenían estas armas improvisadas (DeVries y Smith 2007: 132-133); por otro lado, Riquer documenta que este término también se usaba para ciertas armas de punta roma empleadas en duelos judiciales (1968: 24). No obstante, por el contexto en que aparece en la Chanson, parece innegable que se emplea con una connotación negativa, satírica; connotación que pervive a lo largo de toda la Edad Media: dos siglos más tarde el caballero Bernat de Vilarig usa conscientemente el término en este sentido en un debate teórico con otro caballero: «Vilarig, tozudo, sostenía muy equivocadamente que luchar desmontados no era de estilo caballeresco, pues ello no supone combatir ("combatre") sino pegarse ("batre"), como hace la gente villana» (Riquer 1999: 99).

15 Cabe recordar el tabú existente alrededor del cerdo en la cultura árabe, así como la comparación con perros utilizada como insulto. 
estando en Roncesvalles, los animales no comerán sus cadáveres; y Baligán se jacta de que Carlos no comerá si él no se lo ordena. Observamos, en efecto, un complejo juego de anticipaciones y ecos en el que lo cómico se mezcla con lo grotesco, en el que contrasta la solemnidad religiosa -imbricada con la veneración del cuerpo del guerrero (véase vv. 3685-3695) - aplicada a los francos con la cruda burla sobre la materialidad del enemigo. A pesar de la ausencia de claridad analógica en este entramado (es difícil fijar con precisión qué corresponde a qué), y de que no existe un cuidado para que sea reconstruido y comprendido por el público, sí es unívoco: es imposible entenderlo al revés, invertir sus valores, asignar los moralmente positivos a los paganos y los negativos a los francos ${ }^{16}$.

Cabe mencionar un último detalle de la laisse que puede activar sentidos cómicos, aunque de menor recorrido que el que hemos debido considerar para los "porcs e chen". En la laisse CXCIII, la siguiente a la que contiene la referencia de Baligán a la comida, lo escuchamos proferir otra amenaza, donde usa nuevamente un condicional con la hipótesis de que Carlos sea su vasallo: "s'en ma mercit ne se culzt a mes piez [...] jo li toldrai la corune del chef." (vv. 2682 y 2684). En el marco del funcionamiento narrativo que hemos expuesto, según el cual el momento que se está relatando domina gravitacionalmente pasado y futuro, Baligán reformulará la amenaza anticipando la inminente batalla con Carlos: "bataille i ert, se il ne s'en desolt: / jamais n'avrat el chef corone d'or" (vv. 3235-3236). Como sucedía con las dos escenas de derribo de los ídolos, la comparación nos ayuda a ahondar en las posibles intenciones del/los autor/es. Nuevamente, el retorno al tema es más escueto y solemne: Baligán ya no se imagina enfrentándose a Carlos en un futuro indeterminado, sino que únicamente lanza el aserto de que su oponente jamás volverá a llevar una corona. Por el contrario, aunque no alcance la prolijidad de nuestra laisse, sí se extiende en el fragmento (del que solo hemos citado dos versos) en el que plantea por vez primera la amenaza; y no solo el personaje de Baligán hincha el relato: se nos reproduce también la réplica del pueblo (v. 2685), réplica que falta en la segunda amenaza, donde sería en cambio más lógica como conclusión al catálogo de los caballeros. Cabe destacar además el registro patético si no bajo que introducen los "piez". Y debemos señalar el juego de la laisse entendida como unidad: a la voluntad de desposeer a Carlos de su corona precede la orden de llevar el guante a Marsil; son promesas inversas y fallidas de actos relativos al cuerpo del monarca: ni podrán ponerle el guante a su rey ni quitarle la corona al rey franco. Por un lado, el motivo que se escoge para la conminación basta para evidenciar la voluntad de construir sobre los sentidos de nuestra laisse: quitar la corona, exactamente la misma acción que acaban de perpetrar los paganos contra sus ídolos. Por otro lado, la mención de los "piez", que conecta con "entre lur piez

16 Es coherente con este conjunto de asociaciones - y lo refuerza - el hecho de que todas las descripciones de personajes paganos sean animalizadoras (Edmonds 1971; Maurice 1992: 97). Por lo demás, al exponer este funcionamiento ideológico del texto estamos apoyando desde un punto de vista intrínsecamente literario la tesis defendida en gran parte de las lecturas sociológicas, a saber, la importancia del contexto político del siglo XII en la Chanson; cabe destacar en este sentido la interpretación de Jean Poncet, pues pone el foco precisamente en los episodios de Ganelón y de Baligán para argumentar que estamos ante "un poème profondément engagé" (1970: 129). 
a tere le tresturnent", confirma e incide en el paralelismo. Así, observamos que la recurrencia del motivo subraya la comicidad agresiva, satírica, de la laisse que hemos estudiado, boicoteando cualquier asomo de empatía con los paganos y recalcando su maldad: el pueblo saqueaba los ídolos así como Marsil se deshacía de sus armas, pero al igual también que Baligán — de las estatuas retornamos a otra figura humana, en un vaivén que objetualiza a los paganos - fantasea con quitarle la corona a Carlos. Y esto último es en cambio muy serio, como lo demuestra el hecho de que el texto se encargue de disipar toda duda posible. El conde Ogier, "mult fierement", arenga a Carlos: si no arremete para vengar a sus muertos, "ja Deu ne placet qu'el chef portez corone" (vv. 3536-3539). Y aquí no hay lugar para réplicas ni para detenerse en imágenes: únicamente se nos dice que "n'i ad icel ki un sul mot respundent" (v. 3540), y la laisse concluye con el ataque de los francos. "La procédure de l'interprétation du texte est incorporée dans la structure même du texte médiéval" (Haidu 1978: 464): el público o el lector, como los caballeros de Carlos, solo puede permanecer en silencio ante la osadía de Ogier.

Las coronas son pues, de un modo muy similar a los guantes, estudiados por Rosenstreich, objetos en los que al valor simbólico pasivo (el de un poder que emana de Dios) anterior a la obra literaria se superponen distintos valores activos, construidos a través de las sucesivas interacciones de los personajes. A propósito de esta cuestión, afirma Rosenstreich que los objetos "play their active roles only when they are touched" (2005: 367); así, mientras que la corona de Carlos solo aparece en su valor pasivo, como atributo de su soberanía, la corona de los ídolos, como el guante que Ganelón no coge correctamente, se carga de contenido: indica una falta de adecuación - concepto clave en la ética medieval - a través de, a diferencia del caso del guante, lo cómico. Se trata de un caso más, paradigmático por cuanto la corona es arquetípicamente símbolo de jerarquía, normatividad y por ende seriedad, de lo que hemos tratado de mostrar en este artículo: de cómo lo profundamente solemne puede colorearse de humor, aunque sea tenuemente y en momentos muy delimitados; de cómo incluso aquello que merece el respeto más reverencial puede convertirse en objeto de hilaridad; no en vano la pregunta que pone en marcha el argumento del Pèlerinage de Charlemagne - obra de tono enteramente paródico - es esta que Carlos formula a su esposa: "croyez-vous qu'il y ait un homme sous le ciel qui sache mieux porter couronne et glaive?" (Riquer 1984: vv. 9-10).

\section{BIBLIOGRAFÍA}

AUERBACH, Erich (1988): Mímesis. La representación de la realidad en la literatura occidental. México D.F.: Fondo de cultura económica.

(1998): Figura. Madrid: Trotta.

BACHA, Jacqueline (2004): "L'antéposition de l'objet nominal dans «La chanson de Roland»", L'Information Grammaticale. 100: 22-25.

BALLART, Pere (1994): Eironeia. La figuración irónica en el discurso literario moderno. Barcelona: Quaderns Crema. 
BANDMANN, Günter (2005): Early Medieval Architecture as Bearer of Meaning. Nueva York: Columbia University Press.

BRAULT, Gérard J. (1971): "Structure et sens de la «Chanson de Roland»", The French Review. 45-3: 1-12.

DE MANDACH, André (1993): Chanson de Roland. Transferts de mythe dans le monde occidental et oriental. Ginebra: Droz.

DEVRIES, Kelly; SMITH, Robert D. (2007): Medieval Weapons. Santa Bárbara: ABCCLIO.

DUGGAN, Joseph J. (1973): The Song of Roland. Formulaic Style and Poetic Craft. Berkeley: University of California Press.

EDMONDS, Barbara P. (1971): "Le portrait des sarrasins dans «La chanson de Roland»", The French Review. 44-5: 870-880.

FOUCAULT, Michel (1978): Vigilar y castigar. Madrid: Siglo XXI.

GREEN, Dennis H. (2002): The Beginnings of Medieval Romance. Cambridge: Cambridge University Press.

HAIDU, Peter (1978): "Au debut du roman, l'ironie", Poétique. 36: 443-466.

HEINEMANN, Edward A. (1973): "Composition stylisée et technique littéraire dans la «Chanson de Roland»", Romania. 373: 1-28.

HERMAN, Gerald (1971): "Is There Humor in «La Chanson de Roland»?", The French Review. 45-3: 13-20.

KINOSHITA, Sharon (2006): Medieval Boundaries. Rethinking Difference in Old French Literature. Filadelfia: University of Pennsylvania Press.

MARCHELLO-NIZIA, Christiane (1995): L'évolution du français. Ordre des mots, démonstratifs, accent tonique. Paríi: Colin.

MAURICE, Jean (1992): La Chanson de Roland. Paris: Presses Universitaires de France.

MENÉNDEZ PIDAL, Ramón (1959): La Chanson de Roland y el Neotradicionalismo. Madrid: Espasa-Calpe.

PONCET, Jean (1970): “«La Chanson de Roland» à la lumière de l'histoire : vérité de Baligant", Revue de l'Occident musulman et de la Méditerranée. 8: 125-139.

RAY, William E. (1976): "Pairing and Temporal Perspective in the "Chanson de Roland»", The French Review. 50-2: 243-250.

RIQUER, Isabel de (ed., 1984): Le pèlerinage de Charlemagne. Barcelona: Quaderns Crema.

RIQUER, Martín de (1968): L'Arnès del cavaller. Barcelona: Ariel.

(1999): Caballeros medievales y sus armas. Madrid: Universidad Nacional de Educación a Distancia.

(ed.)(2003): Chanson de Roland. Cantar de Roldán y el Roncesvalles navarro. Barcelona: Acantilado.

ROSENSTREICH, Susan L. (2005): "Reappearing Objects in «La Chanson de Roland»", The French Review. 79-2: 358-369.

SEGRE, Cesare (ed., 2003): La Chanson de Roland. Genève: Droz.

SCHOENTJES, Pierre (2001): Poétique de l'ironie. Paris: Seuil. 
VALLCORBA, Jaume (2010): Lectura de la "Chanson de Roland”. Barcelona: Acantilado.

VANDER, Stefan (2017): The Knight, the Cross, and the Song. Crusade Propaganda and Chivalric Literature, 1100-1400. Filadelfia: University of Pennsylvania Press. WALTER, Philippe (1989): La mémoire du temps. Fêtes et calendriers de Chrétien de Troyes à La Mort Artu. Paris: Champion.

\section{PERFIL ACADÉMICO Y PROFESIONAL}

Roger Navas Solé es estudiante de último curso del grado de Humanidades de la Universitat Pompeu Fabra. Su investigación sobre La chanson de Roland es la ampliación de un trabajo de curso para la asignatura Literatura Medieval Europea impartida por la profesora Victoria Cirlot. Ha publicado un estudio sobre la ironía en Flaubert (Çédille, 2018) y ha participado en el congreso NEUMAS de la Universitat de Barcelona con una comunicación sobre las formas del relato en Pere Calders.

Fecha de recepción: 16/05/2019

Fecha de aceptación: 09/07/2019 